\title{
The role of change management in improving policy effectiveness in the SANDF
}

\author{
Jaco Pietersen, ${ }^{1}$ South African National Defence Force \\ Pieter Steyn, ${ }^{2}$ Cranefield College \\ Jan Meyer, ${ }^{3}$ North-West University
}

\begin{abstract}
Armed forces the world over have three primary functions - force development, force deployment and force employment. Defence policy plays a guiding role in all of these, but it is especially important in establishing the rationale for the creation of credible military deterrence. Usually, a defence policy presupposes the development of armed forces that are effective at executing their mandate, a condition that is measurable in terms of the discipline, skill and quality of the organisation. The study on which this article reports, used this concept to describe how change management - especially by focusing on incorporating effective prioritisation - could enhance the current defence policy. A general analysis of South African defence policy publications indicates that, indeed, the policymakers had thoroughly considered the effectiveness of the armed forces when they wrote the White Paper on Defence of 1996 and the Defence Review of 1998. By 2006, the South African Army had interpreted national defence policy and formulated a future strategy of its own very much in alignment with the "modern system' approach of the original policy publications.
\end{abstract}

The present study suggests that the principal reason for the large variance between defence policy, military capabilities, and real operational demands stems from the lack of effective prioritisation of defence. This article, therefore, concludes that the South African National Defence Force (SANDF) has been largely unsuccessful in complying with the demands of defence policy, irrespective of the fact that the policy by itself may be obsolete and/or inappropriate for the South African context. Furthermore, it is concluded that military effectiveness in meeting current operational demands is also doubtful. Finally, the schizophrenic organisational culture of the defence force may be the primary cause of its moving ever closer to reneging on its constitutional mandate.

\section{ORIENTATION AND BACKGROUND}

The South African National Defence Force (SANDF) is composed of the officially recognised military armed forces of the Republic of South Africa (RSA). It is governed by the government of the day and commanded by the democratically elected president of the country as the commander-in-chief. 
Within two years of democratisation, defence policy was formalised by the publication of the White Paper on National Defence (1996) and the Defence Review (1998). ${ }^{4}$ Three policy prescripts were significant for the development of the capabilities of the armed forces that was to follow: firstly, the injunction that the SANDF force levels, armaments and military expenditure shall be determined by defence policy as it is derived from an analysis of the external and internal security environment. Secondly, it was envisaged that the "SANDF shall be a balanced, modern, affordable and technologically advanced military force, capable of executing its tasks effectively and efficiently", and, thirdly, that the primary role of the SANDF "shall be to defend South Africa against external military aggression". 5

For the first decade after 1994, the SANDF - as an organisation - therefore, had an internal, structural focus. The services dedicated themselves to the deliberate transformation of the organisation, aimed primarily at legitimising the national defence function rather than ensuring the capability of the military to execute its constitutional mandate. ${ }^{6}$ This focus was especially true for the SA Army, since it was not only the largest and least technology-dependent service - and, therefore, destined to absorb the majority of integrating personnel from their former forces - but also because it had not benefited from any new equipment that the SANDF was to acquire through government's Strategic Arms Package (SAP) deal. ${ }^{7}$ Accordingly, the Army was not obliged to implement changes to its doctrine or to absorb new technology in the short term; it was instead forced to concentrate on transforming its structure and organisational culture by introducing a new leadership, command and management paradigm, relinquishing the former staff compartment system in favour of a novel, joint support system, and surrendering its primary mission of the conduct of military operations to a Joint Operations Division.

\section{BACKGROUND TO THE RESEARCH PROBLEM}

It has become clear there is a need for effective prioritisation by the strategic management of the SANDF, since focus had been lost with regard to what is necessary for the SANDF to portray a professional image of being a credible deterrence.

The topic of this article arose from a pragmatic interest in the measure of alignment between South African defence policy (at national level, but including the SA Army's 'future strategy' at service level) and the actual military capabilities, which that policy had spawned. The fact that approved defence policy is well documented and that a consultative Defence Review is published annually implied that sufficient and appropriate data were available for analysis. It is, therefore, also possible to compare the Defence Review of 1998 and its later versions over time, making deductions and conclusions with regard to the evolution of defence policy in general.

\section{STATEMENT OF THE RESEARCH PROBLEM}

The research problem that was investigated within the ambit of this research study was: 
The current lack of effective prioritisation in the Defence Policy prevents the SANDF from fulfilling its mandate properly and consequently restricts it to portray a professional image.

\section{THE RESEARCH QUESTIONS}

The primary research question, forming the crux of this research study, was:

Can current SANDF effectiveness be improved through applying change management in defence policy, especially by focusing on incorporating effective prioritisation?

The secondary research questions, which were researched in support of the primary research question, are listed below:

» Which capabilities does the SANDF need to fulfil its mandate successfully?

» Which organisational policies are required to enable those capabilities to achieve the SANDF mandate?

» Which criteria should be prioritised when appointing personnel to enable organisational effectiveness?

» What should be prioritised when allocating budgets to enable organisational effectiveness?

\section{RESEARCH OBJECTIVES}

The primary research objective of this research study was:

To determine what the most important priorities of the defence policy should be in order to enable the SANDF to execute its mandate effectively and consequently portray a professional image by being a credible deterrence.

The secondary research objectives of this research study are listed below:

» to determine which capabilities the SANDF needs to fulfil its mandate successfully;

» to determine which organisational policies are required to enable those capabilities to achieve the mandate;

» to determine which criteria should be prioritised when appointing personnel to enable organisational effectiveness; and

» to determine what should be prioritised when allocating budgets to enable organisational effectiveness.

\section{RESEARCH DESIGN AND METHODOLOGY STRATEGY}

As this research focused on a specific outcome, applied research served as research type. This had been designed to apply this article findings to solving a specific and existing problem. ${ }^{8}$ 
The research took place in the social world, as the research involved the systems in which people operate, which, in turn, explain why people do what they do, which in turn implies that an 'interpretive paradigm' applied.

While the research was theoretical in nature, both the positivistic and phenomenological paradigms served as basis for the research. As a result, both quantitative and qualitative data were used to support the research findings. ${ }^{9}$

\section{The research method}

Case study research, which originated in the qualitative paradigm, was selected as a research method for this study and this is elaborated below owing to its importance.

Cooper and Schindler state that a full contextual analysis of fewer events or conditions and their interrelations can be achieved by case study research. ${ }^{10}$ The use of qualitative data, with an emphasis on detail, provides extremely useful insight for problem solving, evaluation and strategy. Missing data are avoided and evidence is verified due to the use of multiple information sources.

Yin elaborates on the case study method to collect, present and analyse data fairly. ${ }^{11}$ Yin further states that the choice of research method depends largely on one's research questions. 'How' and 'why' questions seek to explain present circumstances, which is the core purpose of the case study method. Yin adds, "[i]n brief, the case study method allows investigators to retain the holistic and meaningful characteristics of reallife events, such as individual life cycles, small group behaviour, organisational and managerial processes, and the maturation of industries". ${ }^{2}$

Categorising the present study as either 'descriptive' or 'explanatory' is, however, less obvious, since it employed both kinds of knowledge. On the one hand, there are data, facts and empirical generalisations that affirm the actual state of affairs and, on the other, there are theories and interpretations that suggest causes - or plausible explanations - for why objects of scrutiny appear the way they do. ${ }^{13}$ This study focused on examining the prescripts of defence policy and the competency attributes of the South African military. Ultimately, though, the study considered the meaning of the relationship between the two data sets, as described above.

One may therefore typify the study as a qualitative, descriptive analysis, with risk accruing to its theoretical and inferential validity in particular.

\section{Data collection methodology}

The approach used within the ambit of this research was self-administered questionnaires. The data collection methodology can be categorised as follows:

$» \quad$ qualitative data: interviews, observation and questionnaires; and 


\section{DATA VALIDITY AND RELIABILITY}

According to Collis and Hussey, validity is concerned with the extent to which the research findings accurately represent what is happening. ${ }^{14}$ More specifically, it is concerned with whether the data is a true picture of what is being studied. According to Cooper and Schindler, three major forms of validity can be identified, namely content validity, "criterion related validity and construct validity. ${ }^{15}$ Furthermore Cooper and Schindler conclude that, when a measurement method supplies consistent results, it is viewed as contributing to the validity and reliability of the data obtained. ${ }^{16}$

The following aspects pertaining to data validity and reliability were applied during this research study:

» Validity: Content validity was used due to the various hierarchy levels identified within the target organisation. The target organisation was large enough to be representative of the sample frame ${ }^{17}$

» Reliability: The internal consistency method was used to ensure that every item was correlated with every other item across the entire sample and that the average inter-item correlation was taken as the index of reliability. ${ }^{18}$

\section{ETHICS}

According to Saunders, Lewis and Thornhill "ethics refers to the appropriateness of your behavior in relation to the rights of those who become the subject of your work, or are affected by it". ${ }^{19}$

\section{LITERATURE REVIEW}

In an attempt to shape the mind of the reader and to sketch the background of this research - the current SANDF policy - it is important to note that this article starts with an orientation with regard to concepts and a discussion about values, policy, politics, ideology, strategy and doctrine, all of which are related to governance, and, in this context, to defence policy.

The role of change management will also be discussed in order to increase an understanding of the current policy effectiveness of the SANDF, after which a conclusion follows, showing how change management, together with effective prioritisation, could be applied in order to improve the policy effectiveness of the SANDF.

\section{POLICY}

The following sections will discuss the constructs of policy as defined, its value proposition and related concepts.

Policy defined

Some political scientists and specialists in public administration and strategic studies define policy as: 
- $\quad$ policy consists of general directives on the main lines of action to be followed; ${ }^{20}$

- $\quad$ policy is a particular objective or set of objectives; ${ }^{21}$ and

- $\quad$ in general, decisions about what to do are policy decisions, i.e. decisions with a high political input; policy is a guiding principle designed to influence for instance decisions and actions. ${ }^{22}$

The researcher concluded that 'policy' gives guidance on how a government department and its sub-departments should act to achieve particular objectives. In addition, those objectives should preferably be in the best interest of developing the specific department or organisation.

\section{Concepts of policy}

For a variety of reasons, there is a tendency in the Department of Defence (DoD) to use the term 'policy' to describe almost any regulatory document. Concepts such as policy and regulations, are confused with one another. Many military command council officers appear to think that regulations are policy, and they speak of all regulations, directives, instructions and orders, and sometimes even processes and procedures, as policy, whilst forgetting that regulations are the result of policy. According to Grobler, the above are not the same concepts. ${ }^{23}$ Even the statement of a policy in a document does not make the entire document a policy instrument. Policy ranges far more widely than do regulations. Policy is introduced by strategy. It consists of broad guidelines, which are then applied in the detail that is set out in regulations, directives, orders and instructions. ${ }^{24}$ In other words, policy is an explanation or a principle to guide decisions with regard to courses of action, or which provides appropriate guidance to direct governance. Policy does not set out detailed ways to act. ${ }^{25}$ For example, if policy is to wage war, it provides us with a broad indication of what the principle responsibilities of the armed forces, the entire government and even the public at large should be for the specified time of war. At a particular point in time, many other important features of governance may need to be subordinated to the policy to wage war. Although policy should be clearly stated, even at ministerial level, it is often so broadly stated that it is vague and not easy to understand what it should be. ${ }^{26}$ For convenience of analysis and for practical purposes, policy may be divided into levels, but not everything that is ordered is policy.

\section{Interpreting concepts}

Understanding the meaning of concepts or ideas requires much more than consulting dictionaries, let alone the understanding of operational concepts. ${ }^{27}$ It is essential to analyse values, policy, politics, ideology, strategy and doctrine as concepts in the light of literature related to political science, public administration, international politics and strategic studies. ${ }^{28}$ One often sees definitions offered in official documents and presentations, which play no further part in the discussions that follow. It is as though these definitions had never been mentioned. That in itself speaks volumes about the absence of a thorough understanding and use of concepts. This article reflects an attempt 
to share opinions on these defects. One cannot ignore decades of scientific research and professional literature on these subjects or try to interpret them in a vacuum ignoring historically proved experience. It must be remembered that the armed forces are engaged in the field of public administration and not in business administration (or governance).

\section{Values and culture}

Values in policy - In any country, the values held (whether they are perceived as right or wrong) by the supporters of a political party determine the policies of that party. This implies that the politics of the ruling party are aimed at imposing the values of its supporters or, at least, the interpretation by the leader of the party of the value of its supporters. Policies in the most general sense result from the values held by interest groups, pressure groups and political parties. If a political party adopts certain values, it does so with the intention of taking power and turning those values into government policy. Policies are the guidelines for the governing party to run the economy of the country, its finances, education, health, welfare and, of course, its armed forces.

Culture in policies - this means that political parties contend for power to become the government in order to impose their values. Governments are political institutions that may also wish to impose their values upon other states. That is why war is recognised as a political act; it is a struggle to impose one's will on an opponent by means of force. ${ }^{29}$ This consideration of force also requires that, in a democracy, war should be fought within the framework of the values and policies of the government and not simply for the sake of defeating the opponent by any means, including illegal means.

Role of values - a variety of values may link people together in different interest groups, pressure groups and even political parties. Merely "holding values dear", however, is not sufficient; they have to be linked to ensure their application in society. ${ }^{30}$ Without being bound together as policies, they are no more than shared or private values. The Conservative Party under Margaret Thatcher had very strong values, and these were made binding for British society by being adopted as party policy. They were then imposed on Britain as a whole through law. These values appear to have been held so strongly generally that when the Conservatives were succeeded by the Labour Party, the latter barely changed what had come to be accepted by the British public as a whole. ${ }^{31}$

Policies flow from values held in a society-When a majority of voters hold the same values, the policies are not merely the policies of a party, but they may become the policies of the government. ${ }^{32}$ Furthermore, Vickers defines policy as "norms to guide action". ${ }^{33}$ He adds that policy is made up of decisions giving direction, coherence and continuity to the courses of action for which the decision-making body is responsible. Seen in this light, policy can be seen to be broad directives that include the course or direction chosen and within which subordinate decisions are to be made while the policy prevails.

Giving direction - Vickers did not say that policy comprises the decisions, but rather that policy is the result of those decisions that play a particular role, such as 
giving direction, coherence and continuity to the courses of action wanted, or the course chosen by a party - either one wanting to become the government or already in government. ${ }^{34}$ For Vickers, to arrive at policies and to implement them, a political party has to make a variety of decisions. ${ }^{35}$ A political policy itself is a rather wide-ranging guideline on how to act, a course along which to move. All political parties have policies or norms by which they wish to enforce values.

\section{Hierarchy of policy}

Gladden divides policy into four levels for the convenience of analysis and for practical purposes. ${ }^{36}$ The hierarchical levels of policy and policymaking identified by Gladden are:

- Political policy. The policy enunciated by political parties is what is called political policy. Although it can often be sensed all the way down in government, it is usually embodied in vague, broad-brushed, generalised statements, and lacks clarity as to what it will mean in practice. ${ }^{37}$

- Executive policy. This is the policy more clearly enunciated by the minister of a department, e.g. the DoD, and the top level of its officials in order to enable the policy to be enforced. Once a party has gained power, it has to convert the vague statements of political policy into more concretely defined statements of intent that will be used to bring the political policies into effect. The onus rests on the relevant cabinet and with the applicable ministers and their officials to formulate clear statements that will make it possible for the officials to turn political policies into concrete actions that will result in the desired effects. This group's main tasks are to decide on executive policies and overall planning, directing and co-ordinating the policies, and activities of the specific department. ${ }^{38}$

- Administrative policy. This is formulated by the middle levels of officials of a department, also in order to enable them to achieve the goals set by the party in government and then converted into executive policies by the minister and his top senior officials. That is what administration is about here: getting things done. ${ }^{39}$

- Technical or operational policy. This is formulated by the supervisors at the lowest level of authority. This group includes occupations where the main tasks are those that require technical knowledge and experience. The main tasks consist of carrying out technical work connected with the application of concepts and operational methods, and teaching at certain levels. ${ }^{40}$

- Substantive policies Substantive policies are those that are concerned with the essential elements of governance as in running the country. To mention a few, there are foreign policy, but also health, housing, education, justice, police, law enforcement and defence policies. Substantive policies depend on the values held by the members of political parties. ${ }^{41}$ 


\section{National security policy}

The concept of national security is generally thought of as guaranteeing the survival of the nation and the state by using economic, military and political power and exercising diplomacy. ${ }^{42}$ This broadly means:

- externally defending the state against foreign enemies; and

- internally defending the state against revolution, in other words, maintaining the state unchanged.

\section{Defence policy}

Devising defence policies - a governing principle of the Constitution requires the primary role of the SANDF to be defensive, and this is the basis of any South African defence policy. ${ }^{43}$

\section{Determining policy}

Although the concept of 'formulating policy' has much appeal as a simple formula for presenting policy, formulation as a simple framework of headings does not solve the problem of determining policy. ${ }^{44}$ It suggests a presentation movement rather than an intellectual challenge.

\section{Strategy}

The concept 'strategy' is derived from the Greek term stratagema, which means 'to lead or command an army'. The concept of strategy, therefore, is seen as "the art of the General", the art of creating ideal circumstances to overcome an enemy by using force or threat of force ${ }^{45}$

\section{Doctrine}

The term 'doctrine' is derived from the Latin term doctrina, which means the code of beliefs or taught principles. ${ }^{46}$ It is not only a military concept. It can be found and used in a variety of actions or professions. It is important to realise also that in the sense in which it is used today, doctrine is more flexible than principles. The term 'doctrine' has been applied to axioms regarded as fundamental to the conduct of a government's foreign policy. ${ }^{47}$ This was intended to indicate a consistent guide for conduct or action in given circumstances. Frequently, doctrines have the name of a political office holder attached to them as though the particular doctrine was the creation of the politician, for example the Monroe Doctrine, the Truman Doctrine, the Eisenhower Doctrine, the Nixon Doctrine, the Brezhnev Doctrine and the Bush Doctrine. Popper further asserts that indoctrination rests on accepting a given body of knowledge or belief without question. ${ }^{48}$ The researcher believes, however, that education, in contrast, requires one to stand aside from the given body of knowledge and, without commitment, to analyse this body of knowledge critically and objectively. 


\section{CHANGE MANAGEMENT}

How can the concept of change management be utilised to assist in improving the current effectiveness of SANDF policy? For the purpose of this study, the definition of change management that was applied, was one related to the change control process as per the project management context. ${ }^{49}$ It is then necessary to understand that all the changes that are experienced by the SANDF and its staff, could be equated to organisational restructuring which needs to be managed as a project and which contains the requirements for retention of quality. ${ }^{50}$

Kerzner defines the concept of project management as "the planning and controlling of company resources for a relatively short term objective that has been formulated to attain a set of specific goals and objectives through planning, organising and directing". ${ }^{5}$ Meredith and Mantel elaborate on the importance of a project and state that it must be such that senior management could justify establishing a special organisational unit outside the routine structure. ${ }^{52}$ Burke refers to the definition of 'project management' as the most efficient way of introducing change achieved by, amongst others, employing persons skilled in project management - normally including a project manager - who are given responsibility for introducing the change and who are accountable for its successful accomplishment. ${ }^{53}$

All dimensions of project management should be combined into one seamless integrated domain. This integration entails the application of a specific set of skills, tools, knowledge and techniques into a collection of projects, programmes and portfolios to execute the goals and objectives of the organisation. ${ }^{54}$

\section{EFFECTIVE PRIORITISATION}

The following section deals with the various aspects pertaining to prioritisation.

\section{Effective prioritisation defined}

According to Drucker, 'effective' "means successful in producing a desired or intended result", whereas 'prioritisation' means "to designate or treat something as being very or most important". ${ }^{55}$ For example, "the department failed to prioritise safety and thus suffered employee injuries" and "to determine the order for dealing with a series of tasks according to their importance". ${ }^{56}$

\section{Importance of prioritisation}

Prioritisation is the cornerstone of success. When one prioritises, it becomes clear what the most important tasks for the success of the organisation are. This involves identifying goals and objectives that are important in reaching the intended purpose of the organisation and also focusing personnel and activities on those necessary tasks. ${ }^{57}$

Prioritising starts with having clearly stated goals and objectives (derived from the strategy and ultimately the policy of an organisation) in order to fulfil the vision and mission of the organisation, in other words, to communicate clearly what the 
organisation intends to do, where it wants to be in future, and why it is important to achieve the mission. This helps to keep the organisation focused on what is important at any given point in time. ${ }^{58}$

Finding which goals and objectives will be the most important is difficult, but of vital importance. For example, all the employees of a company can be very productive and diligent all day long, but all those efforts will be to no avail if the work being done is not the correct work necessary for the organisation to achieve its purpose.

Steyn et al. assert that effective and efficient leaders need to be wary of the fact that the learning and growth perspective of organisational strategy becomes vital to the success of any organisation in modern times. ${ }^{59}$ The collective creativity of human resources is the single most important intangible asset of any organisation.

Efficiency is doing something very well, although that 'something' might be unnecessary in achieving the required goals and objectives of an organisation. It does not help one to do the wrong thing $100 \%$ correctly, as it still remains the wrong thing, and ultimately the effort wasted. ${ }^{60}$ Effectiveness is doing the right thing correctly, which implies that the strategic management of the organisation has clearly identified and communicated the goals and objectives necessary to fulfil its mandate, and then equipped the employees with all the necessary resources. ${ }^{61}$

Efficiency and effectiveness are not the same thing; effective organisations focus on important tasks and not necessarily on the urgent ones. ${ }^{62}$ Efficiency is part of the internal processes, being the best fit between the internal social components of structure, processes, people, culture and leadership, whereas effectiveness is part of the external processes, being the best fit between the internal structure and the external environment. ${ }^{63}$

Efficiency is thus concerned with time and effort while effectiveness is based on results. Effectiveness indicates whether the task completed was the right task to complete and, furthermore, serves as a very good indicator of the synergy inside the organisation. To be effective, long-term goals should be reached, targets hit and real progress made. It is therefore essential for any organisation to prioritise its tasks correctly. ${ }^{64}$

Before any organisation can set goals or objectives, it needs to arrive at a clear understanding of where the organisation currently is and where it wants to be, in other words what it wants to achieve or which mandate it wishes to fulfil. This means being crystal clear about what is expected and what needs to be achieved. The organisation needs to learn how best to plan strategies in relation to setting goals and prioritising so that it can meet the varied demands of its mandate best fulfil the mandate and strategies. ${ }^{65}$

Prioritising will keep the organisation on course in achieving its goals and objectives. Abraham Lincoln reportedly once said, "[i]f I had 60 minutes to cut down a tree, I would spend 40 minutes sharpening the axe and 20 minutes cutting it down." Thus, Steven Covey calls planning "sharpening the axe" ${ }^{66}$ One has to take time to make time. Prioritising is the difference between being reactive or proactive. When one does not plan, one ends up responding to events of the day as they occur. ${ }^{67}$ 
Vilfredo Pareto (1896) explains the $80 / 20$ principle, which states that roughly $80 \%$ of one's success will come from $20 \%$ of one's inputs. ${ }^{68}$

This suggests that, in general, time spent working out which goals and objectives are most important will be well rewarded, enabling the organisation to achieve several times as much as it otherwise would have achieved - even with less. The natural tendency, however, seems to be to continue doing what is being done, even if it is no longer the most effective or even applicable anymore. ${ }^{69}$ Remember, it is not the quantity done, but rather the value and quality that are of importance. Typically, this distinction creates two dimensions by which all goal-oriented tasks can be categorised for effective prioritisation, namely importance and urgency. ${ }^{70}$

\section{URGENT}

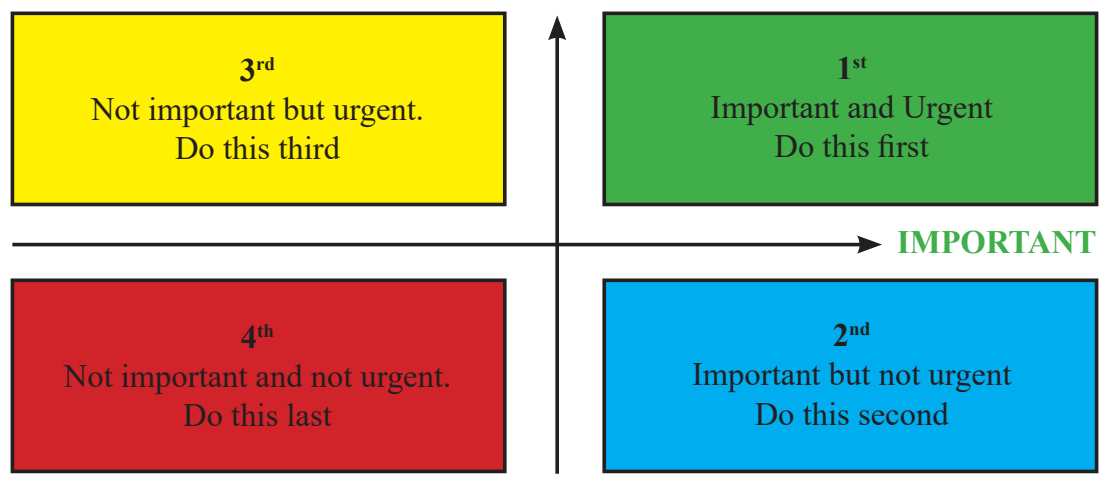

Figure 1: Sequencing priorities. ${ }^{71}$

Barrett elaborates on this concept by saying that the first quadrant - in which the goals are important and urgent - should be avoided at all cost. The urgency, combined with the importance of these goals, creates a sense of panic in the organisation. According to Barrett, the "sweet spot" to be in is the second quadrant where the goals to be achieved are important but not urgent. The culture of the organisation should be of such a nature that proper planning allows for sufficient preparation and resources in order to achieve the goals and objectives effectively. Strategic management, on the other hand, should be of such a nature that the important goals never reach the 'urgent' status.

\section{IMPORTANCE OF COMPETENT LEADERSHIP}

Effectiveness of the decision-making processes lies in the importance of competent leadership. This is confirmed by the words of the well-known former Chief of the American Armed Forces, General Colin Powell, in which he defines leadership as the art of accomplishing more with one's organisation than what the science of management proclaims to be possible. ${ }^{72}$ 
It is common sense that, to be an effective and efficient leader, one should have leadership skills. Owen explains the leadership skills of most importance to be the following: $:^{73}$

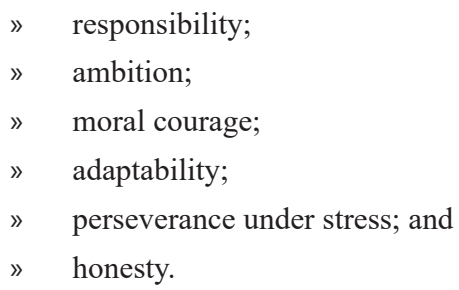

Van Dyk confirms the importance of competent leadership in organisational learning, which, in turn, breeds an organisational culture of "collaboration and cooperation over competition; innovation and pro-action over reactivity". ${ }^{74}$

\section{RESEARCH DESIGN AND METHODOLOGY INTRODUCTION}

In order to satisfy the objectives of the study, qualitative research was used. ${ }^{75}$ While this type of research is especially appropriate for small samples, it is also risky for the results of qualitative research to be perceived as reflecting the opinions of a wider population. ${ }^{76}$ For the purposes of this research, the inductive approach was followed. The main weakness of the inductive approach, however, is that it produces generalised theories and conclusions based only on a small number of observations, and so the reliability of research results may be questioned. ${ }^{77}$ For the purposes of this research, informal interviews incorporating semi-structured questionnaires were used. Informal interviews are unstructured interviews, but they are still personal, and their aim is to identify a participant's emotions, feelings and opinions regarding a particular research subject. ${ }^{78}$

According to the Defence Annual Report for the 2015/2016 financial year the SANDF has approximately 78000 employees. ${ }^{79}$ By applying the theories of Collis and Hussey and focusing on the strategic-level leaders and management officer corps, a representative sample per group was selected and further divided into systematic random sampling owing to the size of the target groups, resulting in the following selection: ${ }^{80}$

- $\quad$ executive management: approximately 260 , from which a representative sample of $50 \%$ was determined; rank group: all generals;

- $\quad$ senior management: approximately 10000 , from which a representative sample of 400 was determined; rank group: staffed qualified officers (colonel and lieutenant colonel); and

- $\quad$ highly skilled supervision: approximately 24000 from which a representative sample of 400 was determined; rank group: senior officers. 


\section{DATA ANALYSIS AND INTERPRETATION OF RESULTS}

The following section will address the empirical findings.

\section{ANALYSIS METHOD}

Content analysis was used to analyse the data, which were gathered from completed questionnaires incorporating personal interviews. According to Moore and McCabe, this is the type of research where data gathered are categorised into themes and subthemes, to enable comparison. ${ }^{81}$ A main advantage of content analysis is that it helps in the data collected being reduced and simplified, while at the same time producing results that may then be measured using quantitative techniques. Moreover, content analysis enables researchers to structure the qualitative data collected in a way that satisfies the accomplishment of research objectives. Human error is, however, highly possible in content analysis, since there is a risk of researchers misinterpreting the data gathered, thereby generating false and unreliable conclusions. ${ }^{82}$

\section{PRELIMINARY ANALYSIS}

Descriptive statistics was applied to all variables, displaying means, standard deviations, frequencies, percentages, cumulative frequencies and cumulative percentages.

\section{INFERENTIAL STATISTICS}

The following inferential statistics were performed on the data:

» chi-square tests for determining association between biographical variables; cross-tabulation and chi-square-based measures of association, a technique for comparing two or more classification variables. It had to be calculated with actual counts rather than percentages; ${ }^{83}$ and

» Cronbach's alpha coefficient, which is an index of reliability associated with the variation accounted for by the true score of the "underlying construct". 'Construct' refers to the hypothetical variables that are being measured. ${ }^{84}$

\section{TECHNICAL REPORT WITH GRAPHICAL DISPLAYS}

A written report with explanations of all variables and their outcome was subsequently compiled. A cross-analysis of variables was performed where necessary, attaching statistical probabilities to indicate the magnitude of differences or associations. All inferential statistics are discussed separately.

\section{ANALYSIS}

In total, 46 questionnaires were completed. The target was 30 only, but eventually 46 were reached. The sample realisation was thus $46 / 30=153 \%, 53 \%$ more than envisaged; thus, proving the survey to be accurate and representative above standard. 


\section{RELIABILITY OF THE RESEARCH INSTRUMENT}

The reliability test (Cronbach's alpha coefficient) was executed on items (statements) representing the measuring instrument of this survey with respect to the responses given in these questionnaires. The Cronbach's alpha coefficient was determined for the ordinal variables in the questionnaire.

All the raw and standardised variables were above 0.70 (near 0.90), which is the acceptable level according to Nunnally, and, thus, the scale proved to be reliable and consistent. ${ }^{85}$

\section{DESCRIPTIVE STATISTICS}

It is important to note that descriptive statistics are based on the total sample. In all the questionnaire, all the questions were answered and none was left out; all questionnaires thus had a $100 \%$ validity.

Statistically it was evident that the majority of respondents (76.09\%) were from the Army service, which is in line with the SANDF force structure, which ensures that the army Service is the leading arms of service, and the other services (Air Force, Navy and Medics) are in support of the army service. In the research 'unit level' refers to the higher strategic level (such as the Chief of the SANDF, or the office of the Minister of Defence with the Secretary of Defence) being Level 1, the different arms of service being Level 2, and the lower tactical levels being 3 and 4 .

The significance of the respondents' unit level indicates the applicability of the target group for this survey, where in general policy is formulated at the highest level 1. The implementation of policy is mainly the responsibility of level 2, with the execution and adherence to policy then primarily having an effect on levels 3 and 4. Thus, as can be seen, the majority of respondents $(67.39 \%)$ came from level 2 , which was relevant to this study because these are the people who have to make policy 'work', whether the policy is effective or not. They are the people who are in the middle who bear the brunt if policy is ineffective and, subsequently, those who have to execute the policy at the lower level keep them responsible if current policy is not relevant any more.

No respondents from unit level 4 (lowest level) were included in this survey. This did not have any influence on the research study since this level has no input into or control over policy. They are merely the executers of policy at the lowest tactical level, and they cannot effect any change to policy.

As previously explained, the focus of this survey was on the Officer Corps of the SANDF in general, and, more specifically, on executive and senior management, because they are the people who effect policy change. The target group for the research was achieved since the majority of respondents were in the rank group of generals (executive management) and staff qualified officers (colonels - senior management), namely $71,74 \%$. They are also the majority of people who can effect policy change, for the same reason as was explained above with regard to unit level. 
For this research, it was crucial to ensure that a fair, realistic balance amongst different ethnic groups was achieved while also being a fair and realistic representation of ethnic numbers in the SANDF. Thus $41,3 \%$ of respondents were White, with an aggregated percentage of 58,7\% and the rest, being African, Coloured and Indian. This is realistically representative of the current SANDF in total; thus, showing that the survey was applicable and accurate.

\section{INFERENTIAL STATISTICS}

The following section will discuss the inferential statistics from an empirical perspective.

\section{Comparison of demographic variables}

The chi-square test was used to test for association between the demographic variables, and it should be noted that only the statistically significant differences are discussed in this article. Furthermore, although the sample was very small, and chisquare tests were not valid as more than $20 \%$ of the outcomes had an expected count of less than 5 in most cases when testing association between the demographic variables, it was done notwithstanding as an indication of association. One way to overcome the small expected count in the cells was to aggregate groups that made sense by combining the lowest two response options on each question in order to increase the frequencies in cells, as chosen by a minority of respondents. This solved the problem of low expected frequencies to a great extent, although it was still an issue in the minority of chisquares. For this research, it was deemed necessary to do a comparison on rank with the measuring instrument.

\section{Rank vs. measuring instrument}

There is a statistically significant association between the ranks of the respondents and the ways they perceived question 2 (Q2), "To which extent do you believe various current national policies, prescripts, government imperatives, etc. enables the SANDF to successfully achieve its vision, namely: Effective Defence for a democratic SA?" (chi-square value $=10.391 ; \mathrm{DF}=4 ; \mathrm{P}$-value=0.034). It was evident that more respondents from executive management rated it negatively than respondents from other groups.

There was a statistically significant association between the ranks of the respondents and how they perceived question 3(a) (Q3a), "To which extent do personnel have an influence on the current SANDF effectiveness?" (chi-square value=15.058; DF=4; $\mathrm{P}$-value $=0.005$ ). It was evident that more respondents from the highly skilled supervision group (senior officers) considered it to have a considerable influence than respondents from other groupings.

There was a statistically significant association between the ranks of the respondents and how they perceived question 3(b) (Q3b), "To which extent does the organisation have an influence on the current SANDF effectiveness?" (chi-square value=10.811; DF=4; $\mathrm{P}$-value $=0.029$ ). It was evident that more respondents from executive management rated it as having a considerable influence than respondents from other groupings. 
There was a statistically significant association between the ranks of the respondents and how they perceived question 3(d) (Q3d), "To which extent does training have an influence on the current SANDF effectiveness?" (chi-square value=15.683; DF=4; $\mathrm{P}$-value $=0.003$ ). It was evident that more respondents from the highly skilled supervision group (senior officers) rated it as having a considerable influence than respondents from other groupings.

There was a statistically significant association between the ranks of the respondents and how they perceived question 5(a) (Q5a), "To which extent should senior/executive leadership positions in the SANDF demonstrate competence as a core values?" (chisquare value $=18.192 ; \mathrm{DF}=4 ; \mathrm{P}$-value $=0.001$ ). It was evident that more respondents from the highly skilled supervision group (senior officers) rated it as of higher necessity than respondents from other groups.

There was a statistically significant association between the ranks of the respondents and how they perceived question 6 (b) (Q6b), "Indicate your satisfaction with discipline as an individual value of the current SANDF senior/executive management" (chi-square value $=10.788 ; \mathrm{DF}=4 ; \mathrm{P}$-value $=0.029)$. It was evident that more respondents from executive management rated it negatively than respondents from other groups.

There was a statistically significant association between the ranks of the respondents and how they perceived question $6(\mathrm{~g})(\mathrm{Q} 6 \mathrm{~g})$, "Indicate your satisfaction with competence as an individual value of the current SANDF senior/executive management" (chi-square value $=13.966 ; \mathrm{DF}=4 ; \mathrm{P}$-value $=0.007)$. It was evident that more respondents from executive management rated it negatively than respondents from other groups.

There was a statistically significant association between the ranks of the respondents and how they perceived question 6 (h) (Q6h), "Indicate your satisfaction with education as an individual value of the current SANDF senior/executive management" (chi-square value $=10.784 ; \mathrm{DF}=4 ; \mathrm{P}$-value $=0.029)$. It was evident that more respondents from executive management rated it negatively than respondents from other groups.

There was a statistically significant association between the ranks of the respondents and how they perceived question 6 (i) (Q6i), "Indicate your satisfaction with skills as an individual value of the current SANDF senior/executive management" (chi-square value $=11.785 ; \mathrm{DF}=4 ; \mathrm{P}$-value $=0.019$ ). It was evident that more respondents from executive management rated it negatively than respondents from other groups.

There was a statistically significant association between the ranks of the respondents and how they perceived question 7 (d) (Q7d), "Indicate your satisfaction with openness and transparency as an organisational value of the current SANDF" (chi-square value $=11.191 ; \mathrm{DF}=4 ; \mathrm{P}$-value $=0.025$ ). It was evident that more respondents from executive management rated it negatively than respondents from other groups.

There was a statistically significant association between the ranks of the respondents and how they perceived question 7(f) (Q7f), "Indicate your satisfaction with people as an organisational value of the current SANDF" (chi-square value=14.580; DF=4; $\mathrm{P}$-value $=0.006$ ). It was evident that more respondents from executive management rated it negatively than respondents from other groups. 
There was a statistically significant association between the ranks of the respondents and how they perceived question 10(a) (Q10a), "To which extent do you believe the SANDF should get involved in Secondary Role Tasks, such as anti-poaching, in order to gain the support from the tax payers of South Africa?" (chi-square value=11.123; $\mathrm{DF}=4$; P-value $=0.025$ ). It was evident that more respondents from the highly skilled supervision group (senior officers) rated it as being more important than respondents from other groups.

There was a statistically significant association between the ranks of the respondents and how they perceived question 10(d) (Q10d), "To which extent do you believe the SANDF should get involved in Secondary Role Tasks, such as border protection, in order to gain the support from the tax payers of South Africa?" (chi-square value=7.466; $\mathrm{DF}=2$; P-value $=0.024$ ). It was evident that more respondents from the highly skilled supervision group (senior officers) rated it as being more important than respondents from other groups.

There was a statistically significant association between the ranks of the respondents and how they perceived question $17(\mathrm{Q} 17)$, "Indicate to which extent you personally believe that cultural diversity influences effectiveness in the Defence Force" (chisquare value $=11.162 ; \mathrm{DF}=4 ; \mathrm{P}$-value $=0.025$ ). It was evident that more respondents from executive management and the highly skilled supervision group (senior officers) rated it as having a considerable influence than the rest.

There was a statistically significant association between the ranks of the respondents and how they perceived question 25(c) (Q25c), "Keeping in mind the SANDF's primary role and function, to what extent may demonstrations receive priority over training?" (chi-square value $=17.898 ; \mathrm{DF}=4 ; \mathrm{P}$-value $=0.001$ ). It was evident that more respondents from executive management believed that it should receive less priority than respondents from other groups.

There was a statistically significant association between the ranks of the respondents and how they perceived question 25(d) (Q25d), "Keeping in mind the SANDF's primary role and function, to what extent may public image receive priority over combat readiness?" (chi-square value $=11.026 ; \mathrm{DF}=4 ; \mathrm{P}$-value $=0.026$ ). It was evident that more respondents from executive management believed it should receive less priority than respondents from other groups.

\section{Ethnic group vs. measuring instrument}

There was a statistically significant association between the different ethnic groups of respondents and how they perceived question 2, (Q2), "To which extent do you believe various current national policies, prescripts, government imperatives, etc. enable the SANDF to achieve its vision successfully, namely: Effective Defence for a democratic SA?" (chi-square value=11.088; $\mathrm{DF}=4 ; \mathrm{P}$-value=0.026). It was evident that Africans rated it more positively than other groups. 
There was a statistically significant association between the different ethnic groups of respondents and how they perceived question 3(f) (Q3f), "To which extent does doctrine have an influence on the current SANDF effectiveness?" (chi-square value $=13.267 ; \mathrm{DF}=4$; $\mathrm{P}$-value $=0.010$ ). It was evident that Africans rated it as having a greater influence than other groupings.

There was a statistically significant association between the different ethnic groups of respondents and how they perceived question 4 (Q4), "Does the SANDF currently apply correct internal budget allocations to achieve organisational effectiveness?" (chisquare value $=10.800 ; \mathrm{DF}=4 ; \mathrm{P}$-value $=0.029$ ). It was evident that whites, coloureds and Asians rated it as being more negative overall than Africans.

There was a statistically significant association between the different ethnic groups of respondents and how they perceived question 6(a) (Q6a), "Indicate your satisfaction with leadership as an individual value of the current SANDF senior/executive management" (chi-square value $=13.744 ; \mathrm{DF}=4 ; \mathrm{P}$-value $=0.008$ ). It was evident that whites, coloureds and Asians rated it more negatively overall than Africans.

There was a statistically significant association between the different ethnic groups of respondents and how they perceived question 6(b) (Q6b), "Indicate your satisfaction with discipline as an individual value of the current SANDF senior/executive management" (chi-square value $=11.541 ; \mathrm{DF}=4 ; \mathrm{P}$-value $=0.021$ ). It was evident that whites, coloureds and Asians rated it as being more negative overall than Africans.

There was a statistically significant association between the different ethnic groups of respondents and how they perceived question 6(d) (Q6d), "Indicate your satisfaction with professionalism as an individual value of the current SANDF senior/executive management" (chi-square value $=11.211 ; \mathrm{DF}=4 ; \mathrm{P}$-value $=0.024$ ). It was evident that whites, coloureds and Asians rated it more negatively overall than Africans.

There was a statistically significant association between the different ethnic groups of respondents and how they perceived question 6(e) (Q6e), "Indicate your satisfaction with integrity and honesty as an individual value of the current SANDF senior/executive management" (chi-square value $=15.295 ; \mathrm{DF}=4 ; \mathrm{P}$-value $=0.004$ ). It was evident that whites, coloureds and Asians rated it more negatively overall than Africans.

There was a statistically significant association between the different ethnic groups of respondents and how they perceived question 6(i) (Q6i), "Indicate your satisfaction with skills as an individual value of the current SANDF senior/executive management" (chi-square value $=12.579 ; \mathrm{DF}=4 ; \mathrm{P}$-value $=0.014$ ). It was evident that whites, coloureds and Asians rated it more negatively overall than Africans.

There was a statistically significant association between the different ethnic groups of respondents and how they perceived question 7(i) (Q7i), "Indicate your satisfaction with discipline as an organisational value of the current SANDF" (chi-square value $=10.993 ; \mathrm{DF}=4 ; \mathrm{P}$-value $=0.027$ ). It was evident that whites, coloureds and Asians rated it more negatively overall than Africans. 
There was a statistically significant association between the different ethnic groups of respondents and how they perceived question 11 (Q11), "Do you believe the current performance of the SANDF in International Peace Support Operations enhances the image of South Africa?" (chi-square value $=16.158 ; \mathrm{DF}=4$; P-value $=0.003$ ). It was evident that whites, coloureds and Asians rated it more negatively overall than Africans.

There was a statistically significant association between the different ethnic groups of respondents and how they perceived question 13 (Q13), "Do you believe the SANDF's current combat readiness will succeed in executing high intensity and high mobility operations within a 72 hours reaction time?" (chi-square value $=21.058$; $\mathrm{DF}=4$; P-value $=0.000$ ). It was evident that whites, coloureds and Asians rated it more negatively overall than Africans.

There was a statistically significant association between the different ethnic groups of respondents and how they perceived question 18 (Q18), "To which extent do you believe the SANDF is currently portraying a professional image in order to obtain the support of the people of South Africa?" (chi-square value=13.649; $\mathrm{DF}=4$; P-value=0.009). It was evident that whites, coloureds and Asians rated it more negatively overall than Africans.

There was a statistically significant association between the different ethnic groups of respondents and how they perceived question 24 (Q24), "To which extent do you believe the SANDF currently prioritises its goals and objectives correctly in order to execute its mandate effectively?" (chi-square value $=9.610 ; \mathrm{DF}=4 ; \mathrm{P}$-value $=0.048$ ). It was evident that whites, coloureds and Asians rated it more negatively overall than Africans.

\section{SUMMARY}

As regards the results obtained through this survey with respect to the demographic variables in the questionnaire, it was evident the majority of respondents were from the army service, which is in line with the SANDF force structure to reflect the army service as being the leading arms of service, and the other services (Air Force, Navy and Medics) being in support of the army service. It is also significant that the majority of responses were from the unit level, which indicates the applicability of the target group for this survey. This is where general policy is formulated on the highest level 1, implementation of policy is mainly the responsibility of level 2, with the execution of and adherence to policy mainly having an effect on the lower levels 3 and 4. It can, thus, be seen that the fact that the majority of respondents came from level 2 was relevant to this study for these are the people who have to make policy 'work', whether the policy is effective or not. They are the people in the middle who bear the brunt if policy is ineffective, and those on a lower level - who have to execute it - keep them responsible if current policy is not relevant any more.

With respect to the results of the measuring instrument, the majority of respondents believed that current policy does not effectively enable the SANDF to achieve its vision, namely 'Effective defence for a democratic SA' successfully, including 'train as you fight, fight as you train.' They were also of the opinion that the state of organisation in 
the SANDF at the time of this study had a significant influence on the effectiveness of the SANDF. Furthermore, at the time of the study, the SANDF did not apply the correct budget allocation to achieve organisational effectiveness. Some respondents were of the opinion that a leader should display core values, such as competence and knowledge to a great extent. The majority of respondents were, however, not adequately satisfied with the display of these values by executive management of the SANDF at the time of this research. It was also found that many respondents were not adequately satisfied with the display of leadership, team work, transparency, integrity, education, ethical approach and skills by the SANDF's executive management at the time of the study. Some respondents were of the opinion that the SANDF should become involved in secondary role tasks, such as anti-poaching, disaster relief, disease control, border protection and rural security to a great extent. Many respondents felt that, at the time, the SANDF did not apply the principle of appointing the most competent person for the job correctly, nor was career management based on competence, performance, skills and seniority (experience). Many respondents were not adequately satisfied with the current display of professionalism in the SANDF and deemed it ineffective and inefficient.

\section{CONCLUSIONS AND RECOMMENDATIONS}

As per the primary research question, "Can current SANDF effectiveness be improved through applying change management in defence policy, especially by focusing on incorporating effective prioritisation?" the recommendations made are dependent on the methodologies of project and programme management, especially applying the principles of change management. This is supported by the conclusions drawn from the results as analysed from the data obtained from the respondents' questionnaire's and elaborated upon extensively in the preceding sections on statistics. The following recommendations in addressing the primary research question are made:

» It is seriously necessary for the state of organisation in the SANDF to apply change management principles in order to increase the effectiveness of the SANDF significantly.

» The cultural differences are evident in the SANDF's lack of effectiveness, and it is important for executive management firstly to admit this and secondly, to rectify it according to guidelines as was discussed in statistics and summary sections (values and cultural. In any military service, there ought to be only one culture and that should be the military culture. Executive management must guard against allowing different ethnic cultures to be used as an excuse for not adhering to international, commonly accepted military ethos and standards. When we operate as culture carriers and are conscious of our cultural membership, we are emotionally attached to our culturally learned categories of thought, and we value them and protect them as an aspect of group identity to the detriment of organisational effectiveness.

» This supports the finding that, at the time of this study, there did not exist a common feeling of organisational goals and standards after integration. In this regard, executive management should also guard against the use of 
transformation and integration to the detriment of military effectiveness, especially after 25 years of democracy in which transformation ought to have been finished.

The following recommendations are made in addressing of the secondary research questions:

» The SANDF should seriously focus on appointing the most competent person for the job in order for career management to reflect the principles of competence, performance, skills and seniority, rather than allowing political ideologies to dictate staffing. The time for affirmative action is over. In order for any organisation to be effective, moral courage should prevail in appointing the best person for the job necessary.

» Defence policymakers should determine the realistic 'need' of the SANDF, such as which function should the SANDF fulfil in the modern era, and then focus on formulating new policy, which would enable the SANDF to fulfil its new mandate towards the tax payers of South Africa.

» Policy dictates future training. Once new policy is determined according to national strategy, applicable training should be the main focus of the SANDF in order to enable the combat readiness, thus fulfilling the need of the specific mandate.

\section{RECOMMENDATIONS IN ADDRESSING THE RESEARCH PROBLEM}

Heitman argues that the Defence Secretariat has not been effective since its establishment in 1995, and the reason is that political imperatives resulted in the appointment of senior civil servants in key posts without their having any defence or civil service experience worth mentioning. ${ }^{86}$ Furthermore:

The SANDF continues to suffer from self-destructive personnel management focused on gender and racial quotas to the near exclusion of practical requirements. It is unable or unwilling to dispense with dishonest and incompetent officers, who have driven out experienced, highly competent officers (irrespective of race, black and white alike) and demoralised those who chose to stay by their being frustrated and compromised by the incompetents.

It is recommended that the policymakers refrain from being idealistic when formulating policy that reflects a utopia, resulting in un-executable mandate. A political decision is urgently needed instead to face hard reality and develop policies that are geared towards creating the best possible defence force for the current circumstances by applying tried and tested scientific approaches. This includes the problem of tolerating under-achievers in the organisation. The training institutions in the SANDF at the time of this research were good, but the problem lay with the instructors being overruled by higher authorities when failing an incompetent student in order for the pass rate to reflect the principle of representivity. 
A balance between the following objectives will always be necessary:

» conventional capability (territorial integrity, foreign relations and peace support operations);

» border protection and rural safety (the possibility of an inclusive rural safety system similar to the old commandos that existed previously); and

» support to the people (disaster relief and humanitarian assistance).

A recommendation from the research is to establish a robust, large-scale conscription type service from which the SANDF can select and retain only the best of the best for a permanent career. The rest, who have already gained valuable skills development training, can be put through a programme of establishing responsible and disciplined youth citizens for employment in the RSA economy. This should, however, be funded by other national-funded skills development programmes and not necessarily by the DoD. Misdirected existing funds, which are being used by government through a variety of other less effective youth programmes, should provide the necessary funding. Furthermore, the salary bill of the current SANDF can be reduced by having servicemen at lower rank levels not permanently employed, as there are too many junior soldiers who cannot all develop into senior ranks and subsequently stagnate and become old, operationally ineffective and medically expensive.

Since the publication of the 1998 Defence Review, the South African government has produced neither a coherent national security strategy nor an updated and relevant defence policy that could serve to guide the development of the SANDF. After achieving its initial objectives (integration, transformation and withdrawal from domestic security), the defence force was left with a policy vision of its future that was not only discordant with the global revolution in strategic affairs, but also with the national revolution in security affairs, effectively a policy vacuum in which the SANDF has had to find its own way. The security risks accompanying government's dereliction were manageable since no military threats seemed to be forthcoming, and the state has entered into collective defence agreements with other countries anyway. It is, however, by no means certain that an SANDF left to its own strategic devices, will be effective when called upon to execute its constitutional mandate. In fact, the study has rendered a description of a delta between the demands of South African defence policy, the military capabilities of the SANDF, and the challenges of South Africa's security context that appears not only to be uncomfortably large but is also growing with the passage of time. At the deepest level, the condition seems to originate from the fact that the SANDF comprises exponents of two incompatible, but equally valid, philosophies: those advocating a modern military system, and those schooled in revolutionary war, that have, through the existence of a permissive military-strategic environment, been allowed to coexist and remain unresolved. The SANDF, therefore has been unable to develop. 


\section{ENDNOTES}

${ }^{1}$ Lt Col Jaco Pietersen born in Vryburg in the Northern Cape and matriculated from the Harrismith High School in the Free State in 1994 joined the SANDF in 1995 and was selected for Junior Leadership training and then officer's formative training. He continued his career at the Armour Corps in Bloemfontein as a junior officer instructor, presenting from basic training for new recruits to permanent force career development courses for senior members. Transferred to the Army Battle School in Lohatla. He was subsequently appointed as an operational Squadron Commander in 1 Special Service Battalion in 2006, where he served in various capacities. On completion of his Junior Command \& Staff Duties course (and promotion to the rank of Lt Col in 2012) he was transferred to Pretoria where he was staffed at Defence Foreign Relations, a sub-directorate of Defence Intelligence. Here he fulfilled various key positions from being the liaison officer at the Africa \& Middle East desk, including the SO1 Protocol and ultimately the SO1 Training responsible for all foreign learning opportunities of the SANDF. This includes being the course leader for the training of prospective Defence Attaché candidates the past 7 years. He attended the Joint Senior Command \& Staff Course in Cuba during 2017/18, and was awarded the best student on course and subsequently received the Cuban Military Merit Medal; the order of "Ignacio Agramonte". Other medals and commendations received are: The General Service medal, the Tsumelo Ikateleho medal with Operational Bar, 10 \& 20 years Good Service medals, UN MONUSCO medal (DRC), UN UNAMID medal (Sudan) and the Mandela medal. In 2018 Lt Col Pietersen successfully completed his academic studies in the field of Programme and Project Management at the internationally accredited Cranefield College, where he obtained his Master's Degree with Cum Laude. He also successfully completed his Senior Management Programme at the University of Pretoria in 2013.

${ }^{2}$ Prof Dr Pieter Gerbrandt Steyn, BSc(Eng) (Pretoria), MBA (Pretoria), DCom (Unisa) is a registered Professional Engineer (PrEng). He founded the consulting engineering and management firm, Steyn \& Van Rensburg (SVR), specializing in electrical, mechanical and structural engineering projects, as well as project management (19701992), he was appointed Senior Lecturer in Business Economics at the University of South Africa (UNISA). Permission was granted by the university authorities to continue as a partner in the consulting firm (1971). He was appointed Professor of Business Economics at UNISA (1976) and during 20 years as a partner in the consulting firm, over 2000 projects were completed by Steyn \& Van Rensburg. Major projects are, inter alia, Game City and The Wheel in Durban, Mandela Square, Standard Bank Head Office, First National Bank's Bank City Complex in Johannesburg, and the new campus development, Teacher's Training College, in Pretoria (now the Faculty of Education, University of Pretoria). He is also a founding member of the Production Management Institute (PMI) of South Africa, and became Founder Chairman of the Institute (1977). He is the founder and Principal of Cranefield College of Project and Programme Management, a South African Council on Higher Education / Dept of Education accredited and registered Private Higher Education Institution offering an Advanced Certificate, Advanced Diploma, Postgraduate Diploma, Master of Commerce Degree, and a PhD Degree. He is also a proponent of the Industry 4.0 Economic Dispensation Project, Programme and Portfolio Management, Project and Programme Management; Project Managing Organisational Performance and Innovative Improvement; Organisational Quality and Performance Management; Transformational Corporate Strategy; Creating High-Performance Project and Process Teams; Strategic Supply Chain Management; Leading and Managing the Learning Organisation. 
${ }^{3}$ Jan Meyer is a Professor and the Deputy Director of the NWU Business School. He completed his South African Air Force career (21 years) as the Logistics Coordinator, AFB Swartkop in 1995 with the rank of Colonel. He then joined Xcel IT as a Project Manager on logistics projects for a period of 7 years moving on to the academia as a Senior Lecturer at Monash (SA) School of IT. After and moving to Milpark Business School and the IIE, finally taking up a position at North West University GSB\&GL in 2012. He was appointed the Acting Director in April 2015 and Deputy Director of the integrated NWU Business School in 2018. A position he still holds. He holds a PhD from the University of Pretoria (2002), Masters in Business Leadership from UNISA (1995), Certificate in Logistics Management from the University of Pretoria (1991) and a Bachelor's Degree in Political Science (UNISA, 1990). He also completed the Graduate Certificate in Higher Education at Monash (Melbourne, 2006). His research interests include the Project Management, Supply Chain Management and Data Security. Other fields of interest centre on ICT4D, Information Knowledge Management, e-Governance and e-Government as well as issues in the public sector. Prof Meyer has published in peer reviewed journals in the above fields. Prof Meyer is also on the editorial committee of accredited journals and conferences.

${ }^{4}$ Department of Defence. "White Paper on Defence". 1996.

$<$ http://www.merln.ndu.edu/whitepapers/SouthAfrica1996.pdf $>$ Accessed on 12 May 2016; South African Government. "South African Defence Review 1998”. 1998. $<$ https://www.gov.za/documents/south-african-defence-review-1998> Accessed on 12 May 2016.

${ }^{5}$ Ibid. p. 7

${ }^{6}$ A Esterhuyse. "Getting the job done: Transformation in the South African military". Strategic Review for Southern Africa 32. 2010. 1-30.

${ }^{7}$ J Sylvester \& A Seegers. "South Africa's Strategic Arms Package: A critical analysis". Scientia Militaria 36/1. 2008. 53.

${ }^{8}$ JA Watkins. "A practical guide for researchers to the preparation of written presentations of academic research". $3^{\text {rd }}$ ed. Cape Town: Lavender Moon, 2016, 45.

${ }^{9}$ Ibid. p 10

${ }^{10}$ DR Cooper \& PS Schindler. "Business research methods". $6^{\text {th }}$ ed. Singapore: Irwin/McGrawHill, 1998, 133.

${ }^{11}$ R Yin. "Case study research: Design and methods". $4^{\text {th }}$ ed. Thousand Oaks, CA: Sage, 2009, 3-4.

${ }^{12}$ Ibid. p. 4.

${ }^{13}$ J Mouton. “Understanding social research". Pretoria: Van Schaik, 1996, 107-118.

${ }^{14} \mathrm{~J}$ Collis \& R Hussey. "Business research: A practical guide for undergraduate and postgraduate students". Hampshire: Palgrave Macmillan, 2009, 204.

${ }^{15}$ DR Cooper \& PS Schindler. "Business research methods". $9^{\text {th }}$ ed. Singapore: Irwin/McGrawHill, 2006, 318-320.

${ }^{16}$ Ibid. p 321

${ }^{17}$ Watkins, op. cit. p49-50.

${ }^{18}$ Ibid. p51.

${ }^{19}$ MNK Saunders, P Lewis \& A Thornhill. "Research methods for business students". Edinburgh Gate: Pearson Education, 2000, 130.

${ }^{20}$ A. Yehezekel. "Public policy-making re-examined"., Pennsylvania. Chandler Publishing Co, 1968, 14-18.

${ }^{21}$ A Ranney. "The study of policy content in political science and public policy”. Chicago, IL: Markham, 1968, 97-103.

${ }^{22}$ L Martin. "Arms and strategy: An international survey of modern defence”. London: Weidenfeld \& Nicolson, 1973, 30-37. 
${ }^{23}$ Grobler, 2016: Interview

${ }^{24} \mathrm{G}$ Vickers. "The art of judgement: A study of policymaking”. Thousand Oaks, CA: Sage, 1995, 32-35.

${ }^{25}$ Ranney, op. cit. p54-58

${ }^{26}$ Martin, op. cit. p102-109

${ }^{27}$ Grobler, op. cit. 2016: Interview

${ }^{28}$ Ranney, op. cit. p99-107.

${ }^{29}$ A Stevenson. "Oxford Dictionary of English". $3^{\text {rd }}$ ed. Oxford University Press, 2015, 1323.

${ }^{30}$ J Conman. "Margaret Thatcher: 20 ways she changed Britain". The Guardian. 14 April 2013. 7-11.

${ }^{31}$ Ibid. p15-18.

${ }^{32}$ Vickers op. cit., pp. 67-69.

${ }^{33}$ Vickers op. cit., pp. 70

${ }^{34}$ Ibid. p69-71

${ }^{35}$ Ibid. p69-71

${ }^{36}$ EN Gladden. “The essentials of public administration”. London: Stapples Press, 1964, 72-84.

${ }^{37}$ Ibid. p72-75.

${ }^{38}$ Ibid. p75-78.

${ }^{39}$ Ibid. p78-80.

${ }^{40}$ Ibid. p80-82

${ }^{41}$ Ibid. p86-89

${ }^{42}$ Martin, op. cit. p115-120.

${ }^{43}$ HR Yarger. "Strategic theory for the 21st century: The little book on big strategy". Carlisle, PA: US Army War College, 2006, 39-44.

${ }^{44}$ Esterhuyse, op. cit. p25-29.

${ }^{45}$ Yarger, op. cit.p13-16.

${ }^{46}$ KR Popper. “All life is problem solving”. London: Routledge, 2001, 160-163.

${ }^{47}$ Ibid. p164-167.

${ }^{48}$ Ibid. p167-168

${ }^{49} \mathrm{G}$ Levin. "Embrace and exploit change as a program manager: Guidelines for success".

Project Management Institute. 2012. Archived from the original on September 30, 2013. Retrieved 14 July 2020.

${ }^{50}$ Vincent Goncalves, Carla Campos "The Human Change Management Body of Knowledge (HCMBOK®)". $20183^{\text {rd }}$ Ed Routledge. $<$ https://www.crepress.com/The-HumanChange-Management-Body-of-Knowledge-HCMBOK-Third-Edition/GoncalvesCampos/p/book/9781138576476> Accessed on 22 July 2020.

${ }^{51}$ H Kerzner. "Project management”. Hoboken, NJ: Wiley, 2006, 4-7.

52 J Meredith \& S Mantel. "Project management". New York, NY: Wiley, 2006, 9-13.

${ }^{53}$ R Burke. "Project management techniques”. Hong Kong: Burke, 2013, 18-21.

${ }^{54}$ E Larson \& C Gray. "Project management”. New York, NY: McGraw-Hill Irwin, 2011, 13-19.

${ }^{55}$ PF Drucker. "Managing for business effectiveness". Harvard Business Review 41/3. 1963. 53-60.

${ }^{56}$ Ibid. p58-60

${ }^{57}$ R Batty. "How to prioritise - META Skills part 4". 2013. <http://www.80000hours.org/2013/04/ how-to-prioritise-meta-skills-part-iv> Accessed on 22 April 2016.

${ }^{58}$ YR Akpoveta. " 6 tools to help you prioritise more effectively". 2014. $</$ https://www.oliveblue. com/6-tools-to-help-you-prioritise-more-effectively/ > Accessed on 22 April 2016.

${ }^{59}$ P Steyn, E Schmikl \& P van Dyk. "Programme managing organisational performance and innovative improvement”. Midrand: Cranefield College, 2016. 
${ }^{60}$ The Difference Between Effectiveness And Efficiency Explained". insightsquared.

2020. $<$ https://www.insightsquared.com/blog/effectiveness-vs-efficiency-whatsthe-difference/\#: :text=The $\% 20$ difference $\% 20$ between $\% 20$ effectiveness $\% 20$ and $\% 20$ efficiency $\% 20$ can $\% 20$ be $\% 20$ summed $\% 20$ up,is $\% 20$ about $\% 20$ doing $\% 20$ things\%20right.\&text=Companies $\% 20$ usually\%20seek\%20to\%20increase,their\%20 operations\%20and\%20sales\%20processes.> Accessed on 17 November 2020.

${ }^{61}$ Drucker, op. cit. p52-60.

${ }^{62}$ Beer, M., "Research in organisational change and development”. Vol. 19. Bingley: Emerald Group, 2011.

${ }^{63}$ Ibid. Chapter 2.

${ }^{64}$ Ibid. Chapter 2

${ }^{65}$ A Coughlan. "Planning: Setting goals and prioritising". DCU Student Learning Resource Portal. Washington, DC: Office of the Vice-President for Learning Innovation and Registrar, 2007.

${ }^{66}$ S Covey. "7 habits of highly effective people”. USA: Free Press, 1989.

${ }^{67}$ L Stack. "The importance of planning and prioritising". Laura Stack: The Productivity Pro. 2010. <https://www.theproductivitypro.com/FeaturedArticles/article00017.htm> Accessed on 17 November 2020.

${ }^{68}$ A Casey. "Good generals let their soldiers die in vain". Adam Casey. 2012. $<\mathrm{http}: /$ www.80000hours.org/2012/10/good-generals-let-their-soldiers-die-in-vain $>$ Accessed on 11 May 2016

${ }^{69}$ Drucker, op. cit. p54-60.

${ }^{70}$ M Barrett. "Effective prioritisation". M Barrett. 2014. < http://tech.opentable.co.uk/ blog/2014/04/28/effective-prioritisation/> Accessed on 17 November 2020.

${ }^{71}$ Ibid. 2014, Online.

${ }^{72}$ Steyn, op. cit. Chapter 1.

${ }^{73}$ J Owen. "The leadership skills handbook: 50 essential skills you need to be a leader". $3^{\text {rd }}$ ed. London: Kogan Page, 2014, 11-75.

${ }^{74}$ P van Dyk. "Managing for organisational performance”. Midrand: Cranefield College, 2017, 209-213.

${ }^{75}$ Collis \& Hussey op. cit. p56.

${ }^{76}$ Yin op. cit. p27.

${ }^{77}$ NK Denzin \& YS Lincoln. "The Sage handbook of qualitative research". $3^{\text {rd }}$ ed. Thousand Oaks, CA: Sage, 2005, 75.

${ }^{78}$ Collis \& Hussey op. cit., p. 101.

${ }^{79}$ Defence Annual Report, op. cit. p65-75.

${ }^{80}$ Collis \& Hussey, op. cit. p115-116.

${ }^{81}$ DS Moore \& GP McCabe. "Introduction to the practice of statistics". $5^{\text {th }}$ ed. New York, NY: WH Freeman, 2005, 86-91.

${ }^{82}$ K Krippendorff. “The content analysis reader”. Thousand Oaks, CA: Sage, 2008, 131-137.

${ }^{83}$ Cooper \& Schindler, 2006 op. cit., p. 499.

${ }^{84}$ Ibid. p216-217.

${ }^{85}$ JC Nunnally. "Psychometric theory”. $2^{\text {nd }}$ ed. New York, NY: McGraw-Hill, 1978, 245.

${ }^{86}$ H Heitman. "South African National Defence Force in crisis". Jane's Defence Weekly. 7 April 2010. 27-31. 